\title{
The purposeful power of effective leadership in an organization
}

\begin{abstract}
The spirited perception says that, leaders are those cultivated bunch of people, who really convert their occupational vision and observations into reality for the bottomless interest of an organization. On the other hand it can be easily stated that, leaders recover the most painful resilience into the delightful paradise for the best organizational splendour along with all the participants just not fight so elevate but to cherish the brilliant win forever. On the other hand it is quite evident that, "purposeful Power" means the inhabitable qualities of leaders. They do share their various qualities with all the subordinates and those are truly inspiring for them to work hard for the satisfactory outcome. It is absolutely desirable for the entire organizational higherarchy to follow the same to generate the brilliant organizational desire to provide the best output for the organization at the end. That is the reason why leaders should construct the excellent organizational synthesis, where they shall be able to accomplish the organizational task in a team and this purposeful power of effective leadership along with their qualitative progressions shall enrich the needful organizational benchmark soon. That is why leaders do think that, they are not the singular winner in their rising organizational stature. They do immediately include their managers as well, who are the absolute replica of those highly compassionate leaders, who regulate the real organizational proceedings in deed.
\end{abstract}

Keywords: leader's brilliance, manager's competence, organizational flow
Volume 2 Issue I - 2018

\author{
Rudrarup Gupta \\ 'Academic Researcher, Management from Kolkata, India \\ ${ }^{2}$ Commercial Manager, Multifarious Projects Group, Kolkata, \\ India
} Correspondence: Rudrarup Gupta, 2Commercial Manager,
Multifarious Projects Group, Kolkata, India,

Email rudrarupgupta2I@gmail.com

Received: December 27, 2017 | Published: January 31, 2018

\section{Introduction}

Leadership is the foremost priority of an organization. So they are in a position to restyle the same at every now and then. On the other hand they are the strategy maker to continue the organizational flow with words and wisdom. They are truly focused and particular to control the entire organizational paradigm and dimension.

In other words both leaders and managers do negotiate their noble responsibilities. This is how they do form the new conceptual flexibility in executing for their upcoming ventures.

\section{Reference: I}

"Nawaz Ahsan, Grafoor Dr. Muhammad Mudasar and Munir Dr. Yasin has described in his article entitled: The Impact of Project Leadership and Team Work on Project Success, which signifies the influence of Project manager's leadership and teamwork going on the project success". ${ }^{1}$

Leaders are the bright organizational stars through the following:

a. Leaders by choice: It is absolutely praiseworthy for a successful leader. Because they do win this position not from their own but from their choice of people. It depends upon the unstoppable dedication of them and the wide contributions, which they are appointed to exhibit for in all the regards. That is the reason why it is the desirable milestone for a leader.

b. Leaders by humanity: Noble humanity is the cosmic prayer for each leader to direct an organization. In this regard leaders are undoubtedly the noble personalities and they do share their noble thoughts to the entire organizational higherarchy. As a result their nobilities are appreciated in the global occupational platform and that is accepted as their patent mantras. So they are joyful in achieving the organizational mission and the human mind simultaneously.

c. Leaders by notion: Any cleared notion enriches the leadership qualities. On the other hand leaders do understand everything through logic, examples and the hard core practicality. It is one of the most significant realities for both leaders and organizations to be into the same track for the communal culmination.

\section{Core competence}

a) Leaders are the undying soul of an organization. Moreover they do drive the entire organizational paradigm in a very meticulous platform right from the beginning. Therefore it is really needful for a leader to ensure the occupational competency within a very short while.

b) Self Desire: It is indeed pivotal to run an organization. In this regard leaders must need the self desire to continue their work in progress and on the other hand they shall be directing their subordinates as per the desire. If the contemplation is true then the desire shall work and that shall enrich the best organizational goal shortly.

c) Presentation Skill: Leaders are the very sound presenter. It is one of the great qualities. Because they do convey everything though this skill only. Both presenters and listeners shall have to have the cleared conception to nurture with various information, which shall create the inhabitable occupational hope at the end of the day.

d) Courageous Spirit: Leaders should have the real propensity to courage their subordinates. So that, it is very advantageous for their subordinates to be inspired and to contribute more. It 
matters a lot from the perspective of the massive organizational outcome and on the other hand remarkable brilliance of those subordinates respectively.

e) Decision Making: It is a very important stage. Because organizational consequence is entirely uncertain. In this regard leaders do have to finalise the decision to regulate the organization and to assure the satisfactory organizational outcome at the end.

f) Understanding: It can change the shape of an organization Moreover Leaders have to understand the follower's need and their needful exposure. So they lead their followers and they provide the promotional exposure as per their existing performance. That is really desirable for their smooth elevation and for the organizational sustainability.

g) Emotional Stand: It is truly inspiring for the leaders to contribute from the core of their occupational endurance. Moreover emotional vibrancy is the prime medium for the leaders to understand the organization and to realise their hopeful followers. In this regard they do bring out the parity in between their coordination and the needful administration. As a result the organization can have the highest occupational standing in deed.

h) Innovative Depth: Leaders are absolutely unbeaten to establish their organizational innovations at every now and then. It is the cosmic reflection of them to contribute in the innovative transparency. On the other hand it shall inspire their followers to initiate the same prestigious platform. As a matter of the fact is the entire organizational richness shall be focused in the near future.

\section{Reference: 2}

a) "Belias Dimitrios and Koustelios Athanasios have described in their article entitled: The Impact of Leadership and Change Management Strategy on Organizational Culture, which presences the impact of leadership and change management strategy on organizational culture".

b) Leaders by stimulation: Leaders do stimulate people at every now and then and this is how they do gain the acceptance and it is absolutely courageous for them to form the constructive community, which works hard and snatches the respective organizational progression at all

c) Leaders by dream: each dream of a leader has the compelling view of professional zeal and the qualitative inclinations. They do drive them towards the occupational primness and that is noteworthy. ${ }^{2}$

\section{Leader's influence}

Leaders are in a prior position to influence the entire organization through their organizational excellence, exposures, remarkable contributions, beautiful adjustments, stunning coordination and most notably their spirited educational primness.

a) Motivation: It is indeed very crucial to develop their employees. On the other hand any organizational procurement does largely depend upon their active employees. So it is truly required to motivate them right from the beginning through promotion, family securities, active participations, global acceptance and so on. As a result organizational productivity shall be exclusively high and that shall be really appreciated in both national and international platform.

b) Education: It is having the utmost importance as per the present contest. Each worker must have the minimum education and they have to drive their occupational stature accordingly. In this regard education is must for the entire higherarchy to drive their decisive paradigm and to prepare for the destined occupational attainments respectively.

c) Participation: It is one of the key aspects in this regard. Because it enhances the confidence and it helps to take the part from front. It is very promising for all the active followers to participate in enriching the organizational stand through their both education and the expansion of intelligence.

d) Training: Leaders do have to understand the need of their organization and they have to train their followers accordingly. This leadership approach shall refine their skills and it shall help them to come up with some handsome occupational solutions. They shall be able to utilise the great "Man Management" to alive the professional goodwill of that organization.

e) Behaviour: It is extremely important as per the modern context. Because one of the prime factors is "Job Satisfaction". But for that polite behaviour is very important. This politeness can change the organizational celerity alongside the everlasting cultural synthesis. It is undoubtedly the great initiative for the leaders to hold the existing man power and to ensure the constructive organizational outcome. Moreover this synthesis shall help for the long-lasting occupational devotion as well.

\section{Conclusion}

Leadership is the stirring discovery, which has the uncompromising tendency to collaborate with robust resources and the assiduous people for their impressive aim to inculcate in connection with the touching professional victory with the exhilarating communal stand in style. In fine it is needless to convey that, leadership practice shall introduce the new chapter of occupational resplendence very shortly, where both leaders and followers shall exhibit their forthcoming professional discovery in the most historic metamorphosis of an organization.

\section{Acknowledgements}

None.

\section{Conflict of interest}

The author declares no conflict of interest.

\section{References}

1. Nawaz Ahsan, Muhammad Mudasar, Munir Yasin. The Impact of Project Leadership and Team Work on Project Success. International Journal of Humanities and Social Science. 2016;6(11):270-278.

2. Belias Dimitrios, Koustelios Athanasios. The Impact of Leadership and Change Management Strategy on Organizational Culture. European Scientific Journal. 2014;10(7):451-470. 